


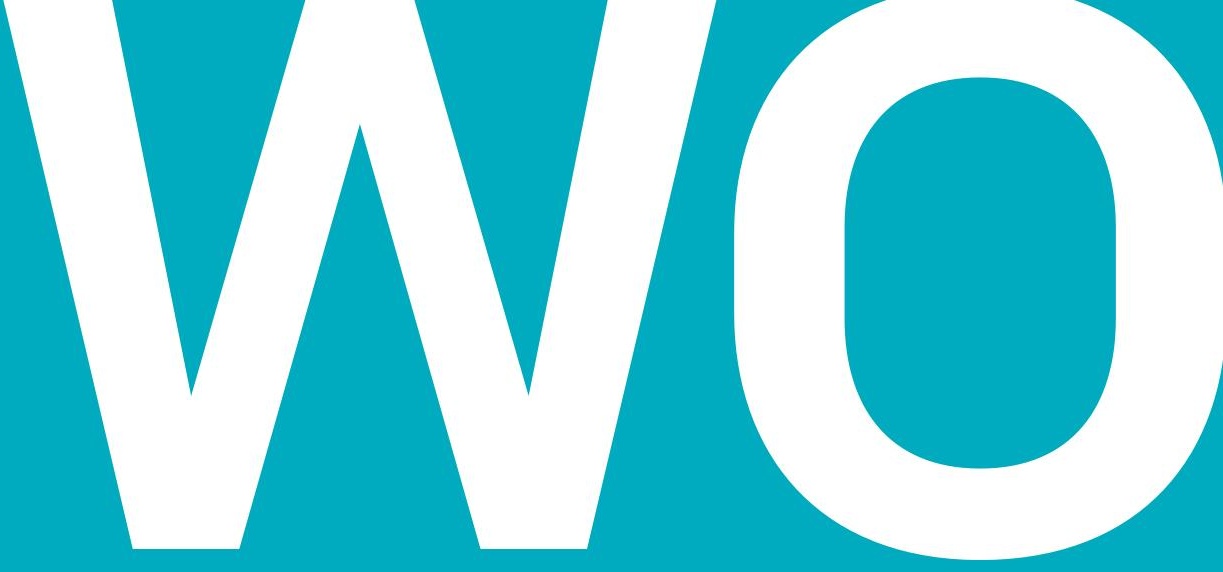

\section{CHAPTER 2 \\ CONSUMER DECISION PROCESS EXPLORATION: LUXURY FASHION PRODUCTS IN BOGOTÁ}

AUTHORS:

Oscar Robayo-Pinzon, PhD. (c)

Politécnico Grancolombiano Institución Universitaria Bachelor's degree in psychology and Master's degree in consumer psychology from Universidad Konrad Lorenz, and researches in the areas of consumer behavior, decision-making models, and brand choice patterns.

Sandra Rojas-Berrío, PhD. Assistant professor, School of Economic Sciences, Universidad Nacional de Colombia.

Diana Giraldo-López, MS.

Politécnico Grancolombiano Institución Universitaria Professional in Business Administration with emphasis in Finances and Master's in Strategic Marketing Management at the Institución Universitaria Politécnico Grancolombiano; with 10 years of experience in commercial area, marketing, customer loyalty, and sales channels. 


\section{INTRODUCTION}

This research aims to explore the factors that are part of the decision process for purchasing luxury fashion products in the city of Bogota (Colombia). The variables of influence that arise from the previous literature (product display, technological accessibility, representation of status, brand perception, lifestyle, association with well-being and wealth, association with delight, motivation of the consumer, authenticity of the product, and cost-benefit ratio) were explored as part of 10 in-depth interviews with people between ages of 25 and 45 who live in strata 5 and 6 in Bogota, Colombia. The validity of the interviews is observed in the verification of concepts with previous research, the quality of the data collected, and, therefore, with the condition of the dependence, credibility, and transferability of these data. The main variables that affect the decision process for purchasing luxury fashion products are the brand, exclusivity, distinction, and their relationship with the positive emotions generated in the consumer. The results of this research suggest how to improve their marketing strategies, focusing on what their target public looks for. This research is the first to analyze the decision process for purchasing luxury fashion products in the city of Bogota by using in-depth interviews.

Well-being and the access to certain goods have been associated with luxury over the years because, since the beginning, these have been associated with the elites (Varsha, et al., 2015; Atwal and Williams, 2009); however, this concept has evolved such that the demand for this type of product is no longer exclusive to developed countries, and developing countries currently represent millions of dollars for this industry (Truong and McColl, 2011).

As a result, luxury goods are no longer exclusive to the elite. The different brands that are representative of those goods have been forced to produce more accessible product lines to meet market demand and that are aimed at giving customers with less purchasing power access to these brands, thus meeting their psychological needs (Sulehri, et al., 2011). These needs are matched to fashion trends, which in turn generate social standards that strengthen the increase in the demand for this type of product (Levy and Luedicke, 2013; Summer, et al., 2006).

Consequently, this research demonstrates the importance of the purchase decision process as a fundamental variable for analyzing the development of the market of luxury fashion goods (Li, et al., 2012).

Considering that there are several studies on this topic in countries with conditions similar to those of Colombia, each country has singularities that correspond to the cultural development and idiosyncrasies of each population. This is therefore expected to 
serve as a basis for the development of marketing strategies and merchandising directed to this type of consumer in a growing market such as that of Colombia (Hung, et al., 2011; Lozano, 2014; Summer, et al., 2006).

Therefore, the goal of this research is to understand the different variables that are involved in the decision process for purchasing luxury fashion products in the city of Bogota. This understanding is expected to be achieved through the identification of the factors that encourage the consumer to buy luxury fashion products, the study of the variables involved in the decision process for purchasing luxury fashion goods and their influence in the decision process of consumers, the categorization of the factors according to their level of relevance, and the establishment of the criteria on which the decision process for purchasing luxury fashion products is based.

\section{LITERATURE REVIEW}

The consumer behavior that leads to the purchase of luxury products is perceived differently in developed countries compared to developing countries (Leung, et al., 2015). Considering that it is a highly competitive market where brands constantly enter, trying to position themselves as differentiated luxury products. This generates the question of how brands come into play in the positioning process, in a scenario in which consumers are driven to demand this type of product (Giovanini, et al., 2015).

Here is where different factors gain importance, such as the display of goods, which also has an impact on the intention to purchase them, which makes it possible to analyze the consumer behaviors of this type of product (Huddleston, et al., 2015). Other factors are the desire for luxury brands, how these are perceived and represent a measure of achievement for consumers, and how these psychologically affect consumers, becoming synonymous with status and a symbol of achievement (McFerran, et al., 2014).

In addition to these factors, the environment in which the market is presently being developed should be analyzed. Due to technology and the accessibility of different brands and collections, it is necessary to develop a globalized strategy that will make it possible to reach different markets and produce the expected impact, especially when the goods must be specific and differentiated and have unique features, as is the case with luxury goods (Simmers, et al., 2014).

That is precisely why the need arises to analyze more than just the market trends and to perform an in-depth analysis of the factors involved in the intention to purchase luxury goods, such as lifestyle and how it affects consumer behavior as well as its relationship with the types of products demanded (Pan, et al., 2014). For example, the case 
of luxury underwear indicates that lifestyle and personal style influence the intention to purchase these goods, in addition to factors such as perception of value, brand concept, and self-image of the consumer; in this case, these factors are used as motivators for creating market demand for this type of product (Hume and Mills, 2013).

Thus, in addition to brand, country of origin has positioned itself as a factor in the purchase decision process to such a degree that there are countries that have already positioned themselves as manufacturers of luxury goods. Therefore, country of origin has become a relevant criterion in the decision process for purchasing luxury goods (Godey, et al., 2012). It has been found that, for consumers, the origin of the goods is directly associated with the level of quality and that this attribute therefore impacts the willingness to pay, which will vary according to the brand and the consumer's perception of the product (Seidenfuss, et al., 2010).

In fact, the operations managers of different brands, in their search for knowing their consumers and their behavior, analyze the response of consumers to their manufacturing practices and production because there is a confirmed interest in knowing what type of labor practices are applied in the production of the products consumed (Aiello, et al., 2009). This causes the phenomenon of ethnocentrism because it is clear that the relationship of the brand and its origin is also relevant to the consumer; therefore, it is a factor within consumer behavior and directly affects the purchase decision process (Javalgi, et al., 2005).

Another factor, and perhaps one of the most important, is purchasing power because it directly influences the purchase decision process. In this process, the intention to purchase becomes increasingly sophisticated; not only does the perception of brand value have an effect, but other factors are also included, such as exclusivity, design, trend, and others that determine the intention to purchase and to pay a higher price for this type of product (Li, et al., 2013).

All of these factors lead to exploring how brands have a psychological impact and how these are part of the purchase decision process, in addition to how the acquisition of this type of product is mainly related to behavioral factors that respond to the search for social approval, the constant search for self-image improvement, and the creation of a prestigious image that is associated with well-being and wealth (Abdolvand and Reihani, 2013).

In turn, these factors are related to a hedonistic concept in which the acquisition of luxury goods is associated with delight, the feeling generated from the purchase. The constant purchase of these goods leads to another factor, the obsolescence of fashion, because, based on trends, consumers generate unmet needs that are covered with constant 
change and innovation (Miller, 2013). This has led to a steady growth in the worldwide figures of this market that is primarily based on options for increasing self-esteem, which is related to the purchase of goods and what the purchase represents for the person and his or her environment (Truong and McColl, 2011).

Furthermore, another factor of influence emerges in which the main motivation develops through the encouragement to follow reference groups, based on the case of some societies that seek to imitate others. This generates a motivation to demand the same class of goods and to develop an appearance that is similar to that of the reference image ( $\mathrm{Li}$ and $\mathrm{Su}, 2007$ ), to the extent that in the constant search for uniqueness, a vintage trend, which intends to revive old fashions, has emerged. Even luxury fashion houses lean toward seeking models from other decades to meet the demand created by this type of product (Cervellon, et al., 2012).

It should also be noted that another phenomenon that has a direct impact on the purchase of luxury goods is the effect of the replicas of this class of products, emphasizing that the type of consumer changes because, even if they experience the same motivations as the habitual consumer of luxury goods, their socio-economic level is different and, therefore, they accept goods of similar appearance but at a lower cost (Hanzaee and Jalalian, 2012). For this reason, it is established that there is a direct relationship between the perception of pleasure through shopping, based on materialism, and brand value, in which culture also has an important role in the purchase decision process. (Shukla, 2012).

Consequently, the impact of the brand on social networks should also be analyzed as part of a globalized culture in which the corresponding measurement needs to be applied to the intention to purchase luxury goods. This intention is directly associated with the index of satisfaction perceived by the consumer who accesses this type of goods (Jin, 2012), considering that the index of satisfaction responds not only to the brand acquired but also to the consumer's association with the brand, including its production process, raw materials, origin, and other characteristics.

In addition, the luxury items market is linked to other factors such as price competition, global supply, and the high volatility of demand due to the socio-economic conditions of the consumer. Therefore, in cases of currency crises, this market is directly affected because, when luxury is not perceived as a primary need, these items can be displaced by the consumption of highly durable goods that are associated with lower costs and priority needs (Bruce and Daly, 2011).

It should be noted that, in a socio-economic environment that changes constantly, in which each economy at a global level has a different dynamic and therefore consum- 
er behavior is also different, there is also a constant process of adaptation to the changes of each economy. This adaptation affects the purchase decision process, starting with the purchase intention, which is determined by the perception of the consumer, and depending on whether the consumer considers the purchase essential or not, it may be replaced even by replicas that represent a lower cost and generate the same psychological sensation (Sulehri, et al., 2011)

Based on this scenario, the impact on brand perception generated by counterfeits can also be analyzed; by associating brands and luxury with uniqueness and the ownership of goods that are seemingly identical but far more affordable in price, the concept of exclusivity would substantially disappear. With the passage of time, however, it has been found that brands still retain their strength and prestige despite the emergence of replicas and counterfeits of their goods (Hieke, 2010)

Nonetheless, it is important to increase consumer awareness of the impacts of the demand for counterfeits in the market because, even if the brand is unaffected, the impact of this phenomenon is transferred to production processes. The reason is that poor work conditions are generated for manufacturers, which, in their search to maintain the competitiveness of their goods, reduce production costs, starting with human capital (Phau, et al., 2009).

In the case of imitations, the useful life of the product is less important in the intention to purchase. The reason is that the preference of the consumer is the product, regardless of whether it is a replica, because the interest in the product is its similarity with the original item and also the price comparison, in which the cost-benefit relationship is greater for consumers, provided that they acquire what they are looking for at a lower cost (Zaichkowsky and Nia, 2000).

As a result, companies have had to focus on the development of the value chain and the development of sell strategies for goods to analyze the behavior and attitudes of consumers and also the influence of how goods are distributed, with the goods' accessibility to the public being essential within the aspects that constitute the purchase decision process (Cang, et al., 2009).

\section{METHODOLOGICAL APPROACH}

Given that the interest is in understanding the psychological variables involved in the decision to purchase luxury goods, this research takes a qualitative approach. Although the behavior of the luxury goods market has been extensively studied, the psychological dimension that supports it has been reduced to the feeling of well-being associated with 
this type of product, and the variables that influence the decision-making process have not been examined in-depth (Leung, et al., 2015).

Qualitative research is designed to understand and analyze phenomena to explore them from the perspective of those who participate in such research in a natural environment and in relation to the context. Thus, for the information obtained to be valid, the population must be understood and the knowledge gained in the responses must be transferred, in addition to that which is perceived through other types of language (Zhan and He, 2012). The scope of this investigation is limited to the population of the city of Bogotá, and the analyzed segment is consumers, both men and women, between ages of 25 and 45 from strata 5 and 6, from whom the information corresponding to the factors that are involved in the purchase process of luxury fashion goods was obtained. Data analysis was performed using the Atlas.ti tool, applying the corresponding coding, on which the amount of information needed was based, for its quantification and analysis in regard to the factors and criteria most noted in the transcripts of the interviews conducted (Corbin, et al., 2008).

The objective of this research is to understand the different variables involved in the decision process for purchasing luxury fashion goods in the city of Bogota, and therefore, this study is exploratory in nature (Creswell, 2013). This research is conducted through the application of in-depth interviews that allow a qualitative analysis that demonstrates how and why the purchase decision of this type of product is made (Bryman, 2006). From this analysis, the information is collected and coded according to dependency, credibility, auditability, and transferability, based on the equivalence of the results obtained with those from previous research on the same subject (Zhan and He, 2012).

\section{Selection of participants}

The sample selected for the study consists of 10 people (men and women) located in the city of Bogota, given that this is the basis of the study, from strata 5 and 6 , ranging from 25 to 45 years of age; considering that these factors have been used in similar studies in other countries (Truong and McColl, 2011; Simmers et al., 2014; Wernerfelt and Cervellon, 2012). Also the persons were habitual consumers of luxury goods. An ethics code was used to establish that the personal data of the participants are confidential and that any other additional information is only used for investigative purposes. To enrich the research, only consumers of this type of product are considered.

\section{Description of the variables}

Given the literature reviewed, the variables to examine are determinants of the decision and the influence of the environment in the context of the purchase of luxury goods, goods, or services. 


\begin{tabular}{|c|c|c|}
\hline CATEGORY & INQUIRY THEMES & AUTHORS \\
\hline \multirow{4}{*}{ Context of the product } & Product display & (Huddleston, et al., 2015) \\
\hline & Technological accessibility & (Simmers, et al., 2014) \\
\hline & Representation of status & (McFerran, et al., 2014) \\
\hline & Cultural Characteristics & (Shukla, 2012) \\
\hline \multirow{3}{*}{ Fashion awareness } & Exclusivity & (Summer, et al., 2006) \\
\hline & Design & (Li, et al., 2013) \\
\hline & Trends & (Pan, et al., 2014) \\
\hline Achievement measures & Consumption desire & (McFerran, et al., 2014) \\
\hline Conception of the brand & Self-image of the Consumer & (Hume \& Mills, 2013) \\
\hline Product origin & Brand perception & (Seidenfuss, et al., 2010) \\
\hline \multirow{4}{*}{ Consumer behavior } & Lifestyle & (Pan, et al., 2014) \\
\hline & $\begin{array}{l}\text { Association with well-being } \\
\text { and wealth }\end{array}$ & (Abdolvand \& Reihani, 2013) \\
\hline & Association with delight & (Miller, 2013) \\
\hline & Consumer motivation & (Truong \& McColl, 2011) \\
\hline Product originality & Authenticity of the product & (Hieke, 2010) \\
\hline Importance of the product & Cost-Benefit ratio & (lan, et al., 2009) \\
\hline
\end{tabular}

Table 1. Description of the variables (own elaboration)

\section{Instruments}

To perform our study, in-depth interviews are conducted because doing so allows a more intimate, flexible, and open conversation and exchange of information; the interview is semi-structured, based on a guide with specific questions. However, questions that will help deepen and obtain more information on the desired topics are included, which is crucial importance when explaining the behavior and attitudes of the consumers of luxury goods.

The interview guide includes demographic questions that allowed to set the target in terms of age, gender, and social class; filter questions to determine whether the persons selected are consumers of these types of goods, goods, or services; structural questions that helped detect the degree of knowledge of these types of goods or goods (brands); and questions about expressing feelings regarding the decision-making process to investigate the variables that influence the decision-making process and also about the antecedents (influence) that provide information on the variables that lead the consumer to purchase luxury goods. 


\section{RESULTS}

\section{Analysis system for processing information}

To conduct this research, semi-structured interviews that make the collected data comparable are applied; for this reason, after obtaining the information from the interviews, there is a pre-coding process that makes it possible to analyze the information.

Therefore, the information analysis process begins with the application of the interviews to gather the information, followed by a process of transcription and organization of the information for its subsequent codification, integration, and analysis.

\section{Semantic network}

To demonstrate the existing connection between the main categories evidenced by the study, this study designs the semantic network shown below, in which the main variables involved in the decision process for purchasing luxury fashion goods converge.

This design is based on the information gathered by the in-depth interviews, in which the respondents expressed that the main variable is the brand, and it is supported by endogenous and exogenous variables that lead the decision-making process to focus on the brand of the product. Clearly, this is in response to specific conditions of the product, for example, that the product is consistent with the trends of the market, that it is original and also represents good status in the social environment, and other conditions that are part of the purchase process as a differentiated experience. An example is the shopping environment, which confirms that the setting is also important in the interaction of the brand with the consumer because, through the acquisition of this type of product, it generates positive emotions that help improve the self-image of the consumer; this indicates that most of the factors involved in the purchase decision process are all interrelated.

It should also be added that in a setting that is increasingly conscious of the environmental impact of buying rapid obsolescence goods or those made from fur, variables such as corporate social responsibility (CSR) are involved in the process. This is linked to the level of income, which is directly associated with the capacity to access this type of product. Consequently, if those who have access to this type of product do not require them, then the supply is discouraged. 


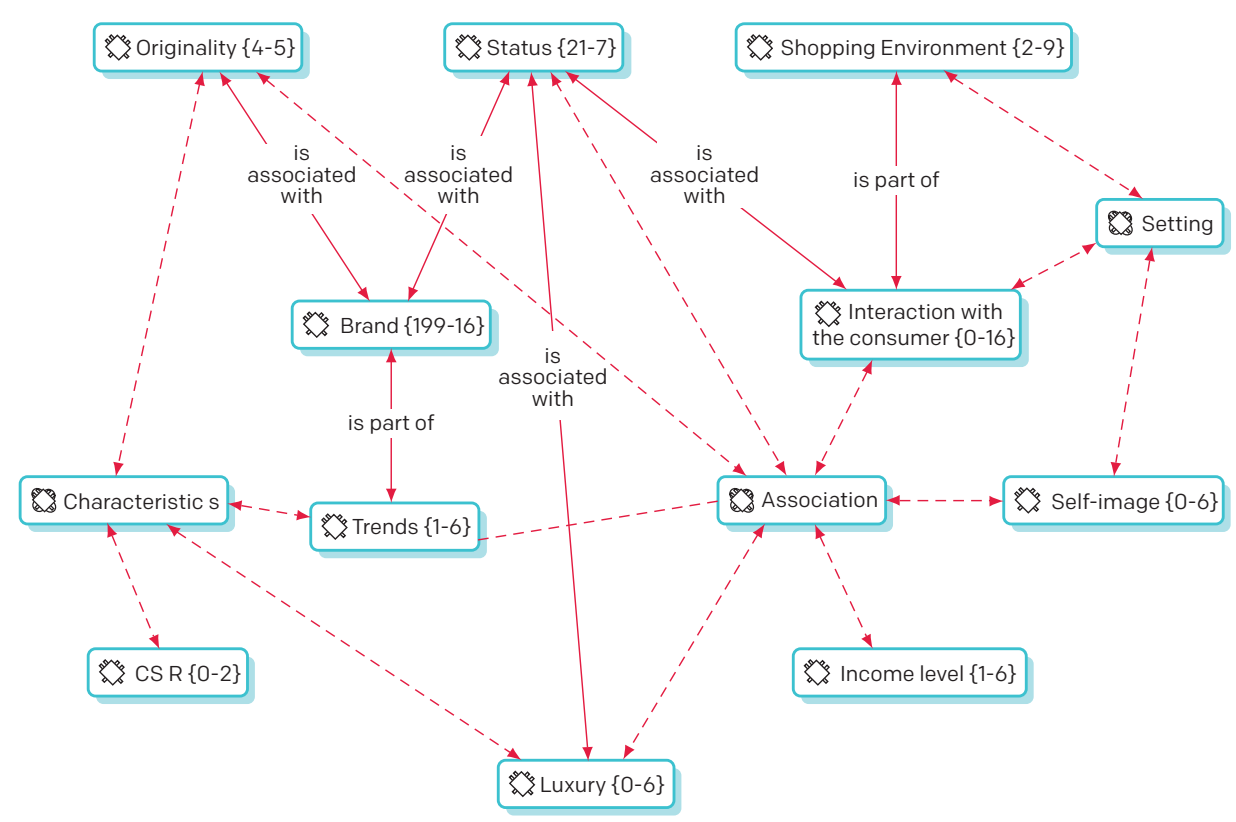

Figure 1. Semantic network (own elaboration)

\section{Dimensions and codes}

Groups corresponding to three macro topics (association, characteristics, and setting) were generated through the codification of the information using ATLAS.ti, and based on these topics, the following dimensions were generated:

- Self-image: This dimension groups the codes that are related to the emotions that arise through accessing luxury goods and contribute to the self-esteem of the consumer.

- Status: In this dimension are the codes that are related to what the purchase of fashion luxury goods represents to the recognition given by the direct customer environment.

- Interaction with the consumer: This dimension groups the codes that are related to how the companies that offer luxury fashion goods relate to consumers and their expectations.

- Luxury: This dimension groups the codes that represent the characteristics and physical and intangible specifications of the product that are associated with luxury.

- Income level: This dimension groups the codes that are associated with the purchasing power and accessibility to this type of product, in addition to those that oppose relating the income level to having access to these goods. 
- Originality: This dimension groups the codes that designate exclusivity and brand distinction with regard to counterfeiting and other types of goods that may distort the value of the product for the consumer.

- Trends: This dimension groups the social, consumer, fashion, and market trends that relate to the demand for fashion luxury goods.

- CSR: This dimension groups the codes related to the awareness of the consumer and of the brands regarding the use of fur and the manufacturing conditions of the goods.

- Shopping environment: This dimension groups the codes that are related to the shopping experience and the environment developed by the brands to provide their consumers a differentiated service model.

\section{ANALYSIS OF THE RESULTS}

The factors that were observed through the codes show how people associate the luxury of the product with the brand, as stated by interviewee 1 (C.P.): "I would think more towards the brand" (P1:50), as well as the association of the brand with recognition and exclusivity, in addition to the conditions of sale and the shopping experience, which are directly related to the value that the consumer is willing to pay, as stated by interviewee 5 (H.C.): "there is a very strong relationship, depending on the design and the brand under consideration" (P6:39). The conditions of sale appeared repeatedly, increasing the density of this dimension above the others, showing that the other variables are components of the brand, and therefore, the brand stood out as the main impact factor in the decision process for purchasing fashion luxury goods in Bogota.

Therefore, in analyzing the interviews, it is found that the decision process for purchasing luxury goods is complex and involves several variables. To conduct this particular study, the following three types of variable groups were generated in the ATLAS. ti software: those related to association (variables that generate a connection between the purchase of luxury goods and emotions, responses from the environment, and distinction), those related to the characteristics (variables that represent the tangible and intangible components of the product), and those related to the setting of the product (variables that represent the characterization of the surroundings and the environment in which the product is presented).

When observing the variables that emerged through the interviewing process, it was found that these do not belong only to a particular type but rather that, in some cases, these are related to each other. Consequently, despite the other factors, it is demonstrated that the brand is what encourages consumers to purchase luxury goods and that 
it is related to the idiosyncrasy of the population, as stated by interviewee 6 (P.R.): "here we are really brand-conscious"(P13:28); and it is supported by variables that constitute the development of the brand, such as distinction and exclusivity. According to interviewee 5 (H.C.), "If I see that it is a good brand and I like it and the brand is exclusive and recognized, I go for it" (P14:23), which in turn is directly associated with the generation of positive emotions in people when they access these goods.

In addition, a long list of components of the purchase decision process originates from these factors. These components materialize through variables such as the setting of the brand, the conditions in which the goods are exhibited and offered, and how the concept of relational marketing is increasingly used to promote sales.

Thus, the brand is tied to the needs of its customers, entering into a process of closeness that establishes a comparative and competitive differentiation of the brand in the mind of the consumer, complemented by a different shopping experience in which consumers find a setting that is designed for their convenience. For this reason, one of the main associations held by the consumer is between the luxury product concept and an environment that is serious, spacious, and organized and that transmits positive sensations that make it possible to focus on the product.

Consequently, the willingness to pay increases because, by accessing this type of product, people buy not only a product but also an entire shopping experience composed of the atmosphere, service, packaging, and the different shopping conditions that may make the purchasing process more pleasurable, as stated by interviewee 2 (L.A.): "spacious environments and environments meant to really influence people to buy the goods" (P10:2). All of these elements are also related to the product perception, which involves variables such as the originality of the product, exclusivity, and the status generated by having access to this type of product.

Accordingly, it is inferred that the purchase of luxury fashion goods is associated with positive emotions such as happiness, satisfaction, and security, among others that were emphasized by the interviewees, for example (C.P.), "the consumption of luxury goods is associated with positive emotions" (P1:20). For this reason, the decision process for purchasing this type of product does not directly depend on the purchasing power of the consumer; although this variable has an impact, it is not the most relevant because some people access these goods through credit cards or consumer finance goods.

Buying these goods responds more to taste for the product and not to the need to have access to them, as stated by interviewee 6 (P.R.): "I think it is more the need than the taste, and wanting to achieve status, more than needing the product" (13:12). 
Everything said up to this point assumes that the variables that correspond to association are the most important and most actively involved in the process of purchasing luxury goods, followed by the factors that correspond to the characteristics, both intrinsic and extrinsic, of the product. These characteristics that correspond to the product mainly include the design, the material, and the differentiation of the product in relation to counterfeits because the increase in the replicas' similarity with the original goods causes their value to be distorted due to the loss of exclusivity.

It should be noted that the characteristics that are most involved in the purchase decision process are the originality of the product, innovation in materials, design, and functionality, provided that these are consistent with the latest trends, without losing the distinctive features of the brand.

In contrast to the above, the variables that comprise the context of the product, despite having less relevance in the purchase process, are used as support for some of the variables of both association and characterization of the product. This may occur because of the atmosphere and presentation of the product; although these variables do not directly affect the purchase process, they are involved in the product perception as part of a differentiated shopping experience, which can complement the persuasion stage that triggers the purchase process of fashion luxury goods.

Specifically, through the findings from the application of the interviews, it was found that the most relevant factor in the purchase process of luxury fashion goods is the brand because of all of its physical components and what it psychologically represents in terms of consumer access to these goods.

Therefore, the criteria that support the decision process for purchasing luxury fashion goods, are the brand, positive emotions, exclusivity, and the status associated

with them, as defined by interviewee 6: "Status is the satisfaction from social recognition" (P13:11).

\section{Schematic of the purchase decision proces}

The schematic of the purchase decision process above shows that by analyzing the qualitative data obtained from the interviews and their respective coding, according to the degree of data concentration in the different variables, it is possible to categorize the factors involved in the decision process for purchasing fashion luxury goods, which is based on the lifestyle from which the consumer's needs or desires are triggered. For this reason, the interaction with the customer becomes extremely important in the process because it leads to knowledge of fashion and trends, thus generating an increase in customers' motivation level based on the perception of the product. 


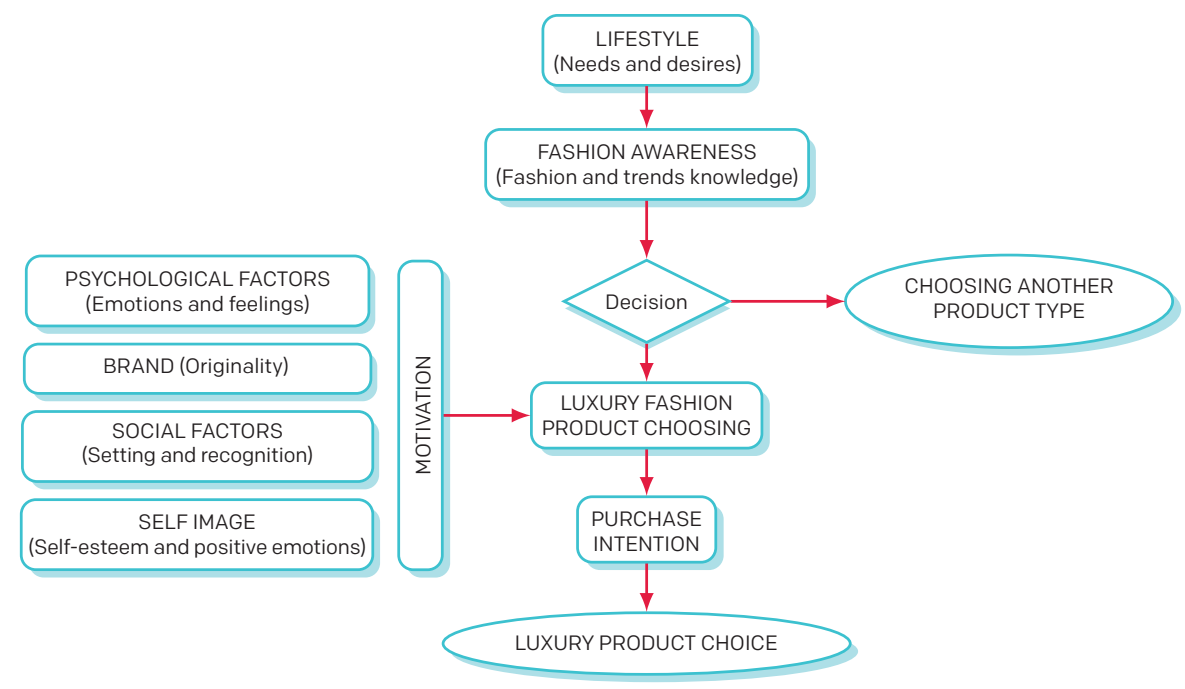

Figure 2. Schematic of the purchase decision process.

Own elaboration from the hermeneutical analysis of the in-depth interviews.

In regard to the psychological factors, motivation responds to the emotions and feelings that the purchase of fashion luxury goods generates in the consumer; regarding the brand, it responds to the image, self-confidence, and satisfaction generated by this type of purchase. The other two factors originate from the brand because the use of luxury fashion goods from socially recognized brands generates the image perceived by the environment and therefore recognition from this environment, which leads to the strengthening of consumers' self-image and, therefore, their self-esteem, through positive emotions as a response to the factors stated above.

It should be noted that this is supported by market trends, in which the main criteria of the purchase decision are based on the brand and all of its components, at the level of presentation, design, service, and associated cost.

\section{DISCUSSION}

The contribution of this research is the description of the decision process for purchasing fashion luxury goods in the city of Bogota; therefore, it serves as a framework for the analysis of this process in other major and intermediate cities nationwide as well as their counterparts in other countries. The reason is that the development of this analysis incorporates the perspectives of the target consumer, in terms of the different factors and attributes of the context, the product, and what the consumer expects to obtain or achieve through the purchase, and also because the process of de- 
veloped countries is different from that of developing countries (Bagheri, 2014). Thus, this research joins the previous bibliographic production as a source for subsequent investigations.

Indeed, the research findings are consistent with those obtained in studies conducted in other countries (Sulehri, et al., 2011; Bagheri, 2014), demonstrating that the shopping environment, the measurements, the differentiated attention, and, in general, the different components of the shopping experience function as inducers to the purchase of the product and affect the consumer perception of the brand through different stimuli, in the same manner in which it has been demonstrated in previous research (Simmers, et al., 2014). It is also demonstrated that the characteristics of the product that influence the consumer are associated with the recognition that these characteristics represent in the direct social environment of the customer as a synonym of status; this factor appears in previous research from countries such as India and Pakistan, representing for their consumers the creation of positive emotions, and providing psychological benefits when they access luxury fashion goods (McFerran, et al., 2014).

It should be noted that at the cultural level, the results differ, even though the economic level in the countries where this type of research was conducted is similar; there is a large discrepancy at the social and cultural level, and for this reason, the defined variables take different values in relation to their environment (Shukla, 2012). Accordingly, it is inferred that the perception of the implicit variables in the purchase decision process is different depending on the country and its culture. An example of this difference is exclusivity, which is assumed as dependent on different factors that mainly respond to the setting in which the investigation is performed (Summer, et al., 2006).

Specifically, to address these types of discrepancies between cultures and the development of their luxury fashion markets, the brands define different product lines that adapt to the specific cultural conditions of the market. In turn, this supports the trend marked by certain brands in some markets compared to others in equal economic and social conditions ( $\mathrm{Li}$ and $\mathrm{Su}, 2007$ ), even when these attempt to standardize the trends on the basis of a constant interaction with the customer to increase the brand attractiveness perceived by the customer (Li, et al., 2013; Kaminakis, et al., 2014).

However, it is found that although the brand is the most influential factor in the decision process for purchasing fashion luxury goods, it must be adjusted according to the social, cultural, consumer, and market conditions; the reason is that, as in a previous research, it is found that the consumer is currently far more aware of fashion and its components. This results in the exigency level that the customer has in regard to offers from the brands available on the market (Pan, et al., 2014). 
Similarly, the product display must be adjusted to the cultural and social conditions of the market, as evidenced in the analysis of the information gathered in this research, because the market determines how the concept of luxury is perceived and associated with the product presentation (Huddleston, et al., 2015).

However, it can be observed that, in fact, the social environment (stratification) has a high influence on the purchase decision process. This finding confirms that lifestyle is directly related to the type of goods demanded (Pan, et al., 2014), in addition to the positive emotions that are reinforced by the purchase of this type of product through the perception of the brand and its collective concept (Hume and Mills, 2013).

This finding contradicts the assertion that one of the relevant factors is purchasing power due to the impact of the demand created by brands on consumers' perception, psychologically impacting them through the association between well-being and the brand, which is the basis for accessing this type of product through credit lines (Abdolvand and Reihani, 2013). For this reason, the consumer accesses the product, even though doing so implies costs related to financing, which means that the desire to spend is greater than the financial variables involved in the purchase process (McFerran, et al., 2014).

Therefore, as evidenced in the analysis conducted through the codification and grouping of codes and their themes, brand perception is one of the strongest incentives of the purchase decision process (Seidenfuss, et al., 2010) because this perception directly triggers the motivation to demand this type of product, in addition to the association with the other variables noted above and those shown in the results of the analysis of this research (Truong and McColl, 2011).

In addition, it is found that consistent with the studies conducted, the acquisition of luxury fashion goods is associated with delight, in which the consumer receives emotional benefits through the purchase of this type of product (Miller, 2013), and that this depends on the authenticity of the product, as stated by interviewee 1: "I feel good about myself buying the original" (P1:13) (Hieke, 2010).

For this reason, the perception of the cost-benefit ratio of those interviewed primarily responds to what the acquisition of fashion luxury goods represents in the perception of their image in their direct environment (Leung, et al., 2015), as interviewee 1 stated, "because people feel more content, safer or more satisfied using something from a luxury brand than from an ordinary brand" (P1:20).

This suggests that the results are not in accordance with the literature review conducted and that they represent a complement to the existing literature. This outcome is obtained from the generation of knowledge through the postulated premises and the 
answers obtained, whose analysis offers a new perspective on the development of the luxury fashion goods market based on the cultural development of a city such as Bogota and, similarly, of the perception of its consumers in regard to the process of purchasing this type of product. This contribution adds value to the existing theory on how consumers perceive the access to luxury fashion goods and the other variables that are involved in the purchase process.

Finally, this research brings a new perspective to the analysis of the purchase decision process, demonstrating that, for the consumer, the product is very important and, even more, the integrity of the supply of luxury fashion goods, which generates demand. Regarding consumer behavior, this research provides a new concept that extends from a purchasing model that is related to purchasing capacity to a model that is more focused on attraction towards positive emotions, strengthening self-image, and response to desires more than to needs.

\section{CONCLUSIONS}

Based on the results presented in the previous section and in contrast to the analysis of the documents consulted, it is demonstrated that even when the decision process for purchasing luxury fashion goods is similar in countries with development conditions that are equal to those of Colombia, this process has some variations; the most representative finding is the importance of the brand, whereas social pressure has less relevance in the purchase decision process (Abdolvand and Reihani, 2013). In Bogota, one of the most cosmopolitan cities in the country, a consumption trend that is mostly driven by fashion trends from world-class brands has been generated. These brands have been entering into one of the most desired markets in recent times for this type of product, based on the rising figures of the sector (McFerran, et al., 2014). It should be added that based on the study conducted, it is observed that the decision process for purchasing luxury fashion goods has a structure that is composed of exogenous and endogenous variables. The endogenous variables are described by consumers as the motivation that makes them acquire this type of product, in addition to psychological factors that contribute to their well-being and self-esteem. Therefore, the endogenous variables are perceived as a component of the lifestyle associated with a differentiated shopping experience. Regarding the exogenous variables, these are described as social as well as consumption and market trends. Additionally, these are determinants in the recognition by the environment and therefore in the representation of status; all of this is associated with the brand and the value perceived through having access to it.

Thus, it can also be concluded that the decision process for purchasing luxury goods in Bogota can be described as a process that, though still composed of internal 
and environment variables, is mostly driven by the positive emotions that are produced in consumers in regard to having access to fashion goods from renowned brands and by the impact that this consumption has on their self-image and on the image of them that the environment perceives.

Consequently, it can be concluded that the criteria that lead consumers to the decision process for purchasing luxury fashion goods are factors that primarily respond to the brand, supported by the influence of the environment, emotions, recognition, and self-esteem, understanding that even when they relate to purchasing power, this type of demand is based more on taste than on the need to access these goods because of the luxury.

Regarding the limitations of this study, the main limitation is the willingness of the people from the defined population to be interviewed due to the time it required. For this reason, in future research, condensing the questions, to reduce the time necessary for the interview and, therefore, to have greater willingness from the base population of the study, is recommended.

Funding details: This work was supported by the Institución Universitaria Politecnico Grancolombiano under Grant number 79843140.

Disclosure statement: We have no conflicts of interest to disclose.

\section{REFERENCES}

Abdolvand, M. and Reihani, N. (2013). "The effect of brand association in psycho-social and psycho-personality antecedents: a conceptual model of conspicuous consumption among youth adults", Research Journal of Applied Sciences, Engineering and Technology, Vol 6 No. 6, pp. 1012-1022.

Aiello, G., Donvito, R., Godey, B., Pederzoli, D., Wiedmann, K.P., Hennigs, O.N., Siebels, O.A. (2009). "Luxury brand and Country of Origin effect: results of an international empirical study", Journal of Marketing Trends, Vol 1 No. 1, pp. 67-75.

Atwal, G. and Williams, A. (2009). "Luxury brand marketing - The experience is everything!", Journal of Brand Management, Vol 16 No. 5, pp. 338-346.

Bagheri, M. (2014). "Luxury consumer behavior in Malaysia: Loud brands vs. quiet brands", Procedia - Social and Behavioral Sciences, Vol 130 No. 1, pp. 316-324.

Bruce, M. and Daly, L. (2011). "Adding value: Challenges for UK apparel supply chain management - a review", Production Planning and Control, Vol 22 No. 3, pp. 210-220.

Bryman, A. (2006). “Integrating quantitative and qualitative research: how is it done?”, Qualitative Research, Vol 6 No. 1, pp. 97-113. 
Cang, P., Wang, S. and Xia, Q. (2009). "Research on the mechanism of retail strategy influencing consumer behavior intention-based on empirical analysis of domestic luxury cosmetics brands", Journal of Donghua University, Vol 26 No. 4, pp. 450-460.

Cervellon, M., Carey, L. and Harms, T. (2012). "Something old, something used: Determinants of women's purchase of vintage fashion vs. second-hand fashion”, International Journal of Retail and Distribution Management, Vol 40 No. 12, pp. 956-974.

Corbin, J. and Strauss, A. (2008), Basics of Qualitative Research: Techniques and Procedures for Developing Grounded Theory, SAGE Publications Inc., Thousand Oaks, CA.

Creswell, J. (2013). “Qualitative, quantitative, and mixed methods approaches”, Research Design, Vol 33 No. 2, pp. 1-26.

Giovanini, S., Xu, Y. and Thomas, J. (2015). "Luxury fashion consumption and Generation Y consumers: Self, brand consciousness, and consumption motivations”, Journal of Fashion Marketing and Management: An International Journal, Vol. 19 No. 1, pp. 22 - 40.

Godey, B., Pederzoli, D., Aiello, G., Donvito, R., Chan, P., Oh, H., Singh, R., Skorobogatykh, I., Tsuchiya J., Weitz, B. (2012). "Brand and country-of-origin effect on consumers' decision to purchase luxury products”, Journal of Business Research, Vol 65 No. 1, pp. 1461-1470.

Hanzaee, K.H., and Jalalian, S. (2012). "Impact of non-price factors on purchase intention counterfeits", Research Journal of Applied Sciences, Engineering and Technology, Vol 4 No. 18, pp. 3313-3322.

Hieke, S. (2010). "Effects of counterfeits on the image of luxury brands: An empirical study from the customer perspective", Journal of Brand Management, Vol 18 No. 2, pp. 159-173.

Huddleston, P., Bridget K., Minahan, S., and Fernandez, R. (2015). "Seeking attention: An eye tracking study of in-store merchandise displays", International Journal of Retail and Distribution Management, Vol. 43, No. 6, pp. 561-574.

Hume, M. and Mills, M. (2013) “Uncovering Victoria's Secret: exploring women's luxury perceptions of intimate apparel and purchasing behaviour", Journal of Fashion Marketing and Management: An International Journal, Vol 17 No. 4. pp. 460-485.

Hung, K, Chen, A., Peng N., Hackley, C., Tiwsakul, R., and Chou, C. (2011) "Antecedents of luxury brand purchase intention", Journal of Product and Brand Management, Vol. 20 No. 6, pp.457 - 467.

Javalgi, R., Khare, V. P., Scherer, R. and Gross, A. (2005). "An application of the consumer ethnocentrism model to French consumers", International Business Review, Vol 14 No. 3, pp. 325-344.

Jin, S. (2012) "The potential of social media for luxury brand management", Marketing Intelligence and Planning, Vol. 30 No. 7, pp.687 - 699.

Kaminakis, K., Karantinou, K. and Boukis, A. (2014). "The mediating role of self-concept discrepancy in the relationship between values and personal based motivation of luxury products consumers", Procedia - Social and Behavioral Sciences, Vol 148 No. 1, 619-624.

Leung, A., Yee, R. and Lo, E. (2015). "Psychological and social factors of fashion consciousness: An empirical study in the luxury fashion market", Research Journal of Textile and Apparel, Vol 19 No. 3, pp. 58-69.

Levy, S. J. and Luedicke, M. K. (2013). “From Marketing Ideology to Branding Ideology”, Journal of Macromarketing, Vol 33 No. 1, pp. 58-66.

Li, G., Li, G., and Kambele, Z. (2012). "Luxury fashion brand consumers in China: Perceived value, fashion lifestyle, and willingness to pay”, Journal of Business Research, Vol 65 No.10, pp. 1516-1522. 
Li, J. and Su, C. (2007). "How face influences consumption: a comparative study of American and Chinese consumers”, International Journal of Market Research, Vol 49 No. 2, pp. 237-256.

Li, N., Robson, A. and Coates, N. (2013) “Chinese consumers' purchasing: impact of value and affect”, Journal of Fashion Marketing and Management: An International Journal, Vol. 17 No. 4, pp.486 - 508.

Lozano, R. (2014), "Marcas de lujo hacen su agosto en un país cada vez más pudiente [Luxury brands make a killing in an increasingly wealthy country]", available at: http://www.eltiempo.com/ economia/empresas/marcas-de-lujo-en-colombia/14427379 (accessed February 20 2016).

McFerran, B., Aquino, K. and Tracy, J. (2014). "Evidence for two facets of pride in consumption: Findings from luxury brands", Journal of Consumer Psychology", Vol 1 No.1, pp. 1-17.

Miller, K. (2013). "Hedonic customer responses to fast fashion and replicas", Journal of Fashion Marketing and Management: An International Journal, Vol 17 No. 2, pp. 160-174.

Pan, Y., Luo, L., Liu, D., Gao, L., Xu, X., Shen, W., Gao, J. (2014). “How to recommend by online lifestyle tagging (OLT)", International Journal of Information Technology and Decision Making, Vol 13 No. 6, pp. 1183-1209.

Phau I., Sequeira M. and Dix, S. (2009). “Consumers' willingness to knowingly purchase counterfeit products”, Direct Marketing: An International Journal, Vol 3 No. 4, pp. 262-281.

Seidenfuss, K., Kathawala, Y. and Dinnie, K. (2010). "Assembly and component origin effects: an ASEAN consumer perspective", Journal of Consumer Marketing, Vol. 27 No. 6, pp. 488 - 498.

Shukla, P. (2012). "The influence of value perceptions on luxury purchase intentions in developed and emerging markets", International Marketing Review, Vol. 29 No. 6, pp.574 - 596.

Simmers, C., Parker, R., and Schaefer, A. (2014). "The importance of fashion: The Chinese and U.S. Gen Y perspective”, Journal of Global Marketing, Vol 27 No. 2, pp. 94-105.

Sulehri, N., Malik, F., Anjum, N. and Qureshi, W. A. (2011). “Consumer behavior slide down for purchase of luxury brands in Pakistan: A conceptual framework", European Journal of Economics, Finance and Administrative Sciences, Vol 28 No. 1, pp. 189-194.

Summer, T., Belleau, B., and Xu, Y. (2006). "Predicting purchase intention of a controversial luxury apparel product”, Journal of Fashion Marketing and Management: An International Journal, Vol. 10 No. 4, pp. $405-419$.

Truong, Y. and McColl, R. (2011). "Intrinsic motivations, self-esteem, and luxury goods consumption", Journal of Retailing and Consumer Services, Vol 18 No. 6, pp. 555-561.

Varsha J., Subhadip R., Ashok R. (2015) “Conceptualizing luxury buying behavior: the Indian perspective", Journal of Product and Brand Management, Vol. 24 No. 3, pp.211 - 228.

Wernerfelt, A. and Cervellon, M. C. (2012). "Knowledge sharing among green fashion communities online: Lessons for the sustainable supply chain”, Journal of Fashion Marketing and Management: An International Journal, Vol. 16 No. 2, pp. 176 - 192.

Zaichkowsky, J. L. and Nia, A. (2000). “Do counterfeits devalue the ownership of luxury brands?”, Journal of Product and Brand Management, Vol. 9 No. 7, pp.485 - 497.

Zhan, L. and He, Y. (2012). "Understanding luxury consumption in China: Consumer perceptions of best-known brands", Journal of Business Research, Vol 65 No. 10, pp. 1452-1460. 


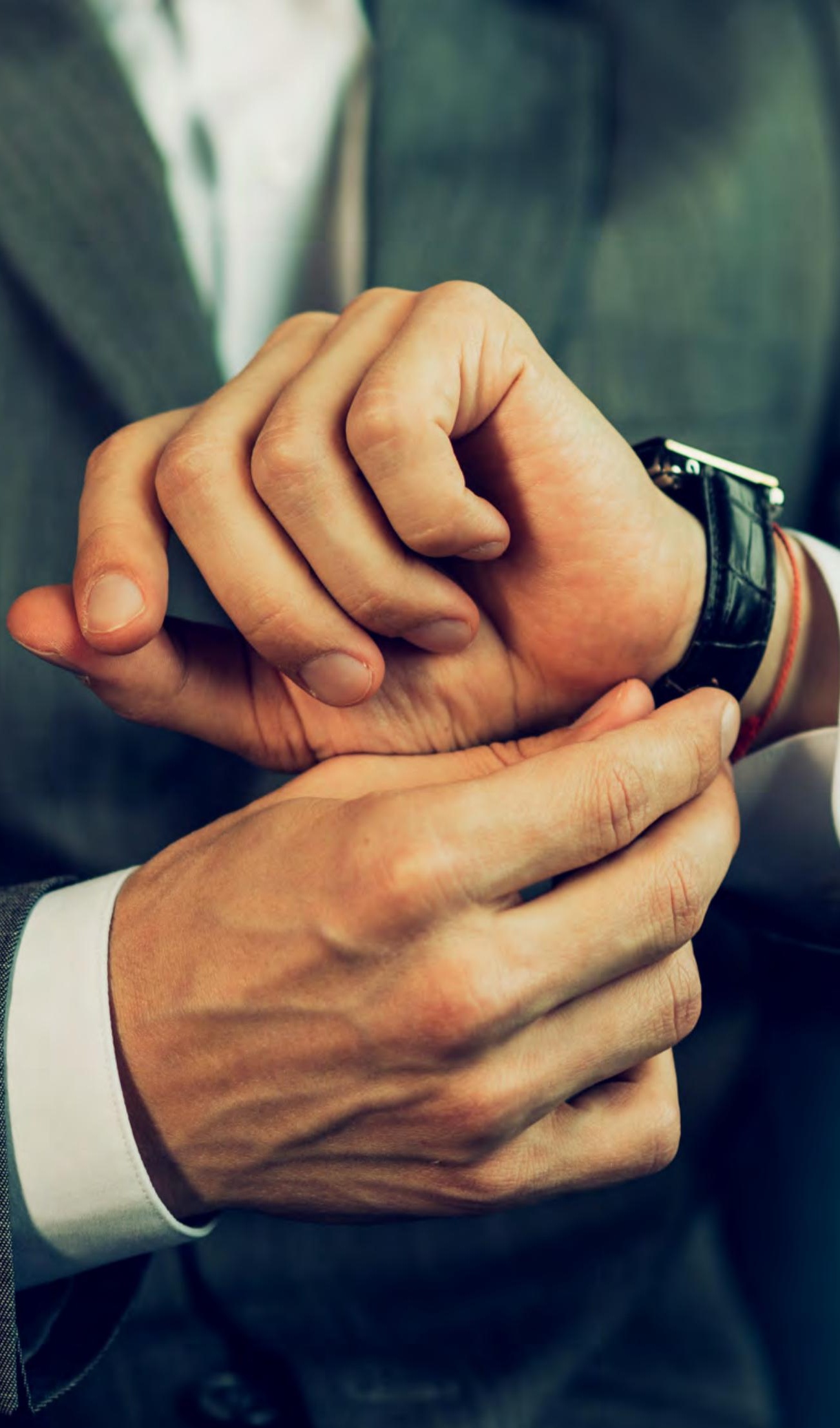

